\title{
FACTORS INFLUENCING THE WEIGHT GAIN OF PIGLETS DURING THE NURSING PERIOD: PRELIMINARY RESULTS
}

\author{
M. Johansen, L. Alban, H. D. Kjorsgaard and P. Baekbo \\ Danish Bacon and Meat Council, Copenhagen. E-mail corresponding author: mjo@danishmeat.dk
}

In intensive pig production the weight of the weaned piglet has significant influence on the pig's later performance. The objective of this study is to estimate the relative impact of genetics, feeding, housing, and health factors on the weight gain during the nursing period. The study was performed as a cohort study in 3 farrow-to-finish herds. A technician visited the herds weekly and collected information on: laying behaviour of sows and piglets, hygiene in the pen, number of functional teats, adjustment of farrowing rail, capacity of water supply for sows and piglets, leg position of sows, as well as presence of inflammations, wounds, ulcers or lesions on the body or on the legs/hoofs of the sows, and forelimb skin abrasions in piglets. The observations were made in the 1 st and 3rd week after farrowing for each litter. The farmer recorded: boar id, sow id, date of transfer, sow weight when entering the farrowing pen, farrowing date, sow weight at weaning, individual piglet weight at birth and at weaning, sow feed consumption in farrowing pens and on the weaning day, cross fostering, piglets weak at birth, and disease treatments of sows and piglets. Average daily weight gain (ADG) for the individual pig was used as response in a linear mixed model, where sow, pen and farrowing date were included as random effects. The significant factors were tested for interaction at sow and pig level, respectively. A total of 8,231 piglets were included in the analysis.

Table 1. Factors ${ }^{\mathrm{a}}$ associated with average daily gain in the nursing period

\begin{tabular}{lcr}
\hline Variable & ESTIMATEg/day/pig & P-VALUE \\
\hline Weak pasterns & 13.96 & 0.0084 \\
Birth weight, per 100 gram & 8.54 & $<0.0001$ \\
Female compared to male & 3.63 & 0.0001 \\
Sow feed intake at weaning b & 1.86 & 0.0047 \\
Forelimb skin abrasion in piglets & -5.21 & $<0.0001$ \\
Sagging udder 3 weeks pp & -13.79 & $<0.0001$ \\
Unthrifty piglets & -20.85 & 0.0002 \\
Arthritis in piglet & -36.23 & $<0.0001$ \\
Diarrhoea in piglet & -47.25 & $<0.0001$ \\
\hline
\end{tabular}

a : Random effects not stated

b: The estimate of the effect on ADG is calculated per 1 feed unit for pigs $\sim 1 \mathrm{~kg}$ barley

The results show that constitution and feed consumption of sows, birth weight; sex, and health of piglets as well as the random effect terms (sow, pen*farrowing date, and farrowing month) were significantly associated with the ADG during the nursing period (Table 1). However, as the data originate from 3 herds only, generalisation should be made with caution. The effect of genetics (boars) was not significant (NS) when month was included in the model. As age of sows and capacity of water supply for sows were not recorded for all sows, these factors were not included in the model. The 
effect of sow age was NS, but was confounded with the effect of weak pasterns. The effect of litter size and sow feed consumption in farrowing pens were explained by other variables in the model. There was no effect of herd on the ADG, probably because most of the variation between herds was explained by the random effect terms. This study indicates that the farmer may influence the ADG in particular by: 1) Ensuring the health of sows and piglets, 2) Maximising the feed intake in sows during lactation.

\title{
METABOLIC CHALLENGES IN LATE PREGNANCY IN MULTIPAROUS EWES FED SILAGE OR HAY
}

\author{
Nørgaard P, Nielsen $M O^{1}$, Christensen A, Kicerskou $H^{1}$, Ranvig H, Thamsborg SM \\ \& Ingvartsen, $K L^{2}$
}

\begin{abstract}
Dept. of Animal Science \& Animal Health and ${ }^{1}$ Dept. of Anatomy \& Physiology, The Royal Veterinary and Agricultural University, Frederiksberg, Denmark,

${ }^{2}$ Department of Animal Health and Animal Welfare, Danish Institute of Agricultural Sciences, Tjele, Denmark
\end{abstract}

A high risk of ketosis has been observed in ewes bearing multiple foetuses and fed poor quality forages. This study investigated metabolic adaptation in the peri-parturient period in multiparous ewes fed low quality forages. Two groups of 4 ewes, 3-5 years old, bearing 2 and 3 foetuses respectively, based on ultra soundscanning, were used. Poor quality grass was harvested and conserved as either long cut silage (GS) or artificially dried, chopped hay $(\mathrm{CH})$. The two forage types were fed ad libitum to the 2 groups of sheep from day 40 prepartum until parturition in a balanced block design. Fish meal, $100 \mathrm{~g}$, was fed daily from day 26 prepartum. Postpartum, all ewes were fed $\mathrm{CH}$ ad libitum and nursed 2 of their own lambs. To ensure growth of the lambs, sheep bearing 3 foetuses and fed GS during pregnancy were fed $500 \mathrm{~g}$ whole barley daily postpartum. Eating and chewing activity were recorded continuously for 96 hours at day 33, 19 and 5 prepartum. Blood sampled were collected on day $-44,-30,-14,-5$ to $+1,+5,+13$ and +26 postpartum. Faeces was sampled weekly for faecal egg counts. Dry matter intake increased significantly from 47 to $56 \mathrm{~g}$ per kg BW ${ }^{0.75}$ from pre- to postpartum, and was significantly $(\mathrm{P}<0.05)$ lower the last 5 days prepartum in ewes bearing 3 compared with 2 foetuses, regardless of forage type. The estimated Net Energy intake prepartum covered only $50 \%$ of ARC energy requirements. Intake of metabolizable protein was $20 \%$ lower in sheep fed GS compared to $\mathrm{CH}$. The mean body condition score (BCS) decreased from 3.0 at day 30 prepartum to 2.0 at day 8 postpartum. The mean BCS was one unit lower $(\mathrm{P}<0.01)$ eight days postpartum in sheep fed GS prepartum. On average, sheep spent 6.0 hours eating and 13 hours chewing (eating + ruminating) prepartum, with the GS fed sheep bearing 3 foetuses spending an additional 1.6 hours chewing $(\mathrm{P}<0.01)$. Plasma glucose concentrations averaged $2.6 \mathrm{mM}$ and $3.2 \mathrm{mM}$ pre- and postpartum, respectively. Sheep fed GS had $0.6 \mathrm{mM}$ lower glucose concentration prepartum than sheep fed $\mathrm{CH}$ $(\mathrm{P}<0.001)$. The average -bhydroxybutyrate and acetoacetate concentrations in the GS and CH groups were 2.9 and $0.2 \mathrm{mM}$ prepartum and 1.6 and $0.1 \mathrm{mM}$ postpartum, respectively. The highest -bhydroxybutyrate concentrations of 4-5 $\mathrm{mM}$ were observed 3-5 days prepartum in sheep bearing 3 foe- 
tuses and fed GS. NEFA concentrations increased from $0.5 \mathrm{mM}$ day 40 prepartum to $1.2 \mathrm{mM}$ at parturition, and declined to $0.3 \mathrm{mM}$ over the next four weeks postpartum. All foetuses identified at scanning were born fully developed, despite severe under-nutrition, decreasing BCS, and blood parameters indicative of subclinical ketosis with advancing pregnancy. Lambs born as twins tended to grow faster $(291 \pm 49 \mathrm{~g} / \mathrm{d})$ than triplets $(239 \pm 54 \mathrm{~g} / \mathrm{d})(\mathrm{P}<0.16)$ from birth to day 22 . In the peri-parturient period, the four ewes fed GS prepartum had a mean faecal egg count of 600 eggs per $g$ of faeces, approx. 5 times higher than for ewes fed $\mathrm{CH}$ prepartum. In conclusion, the present study demonstrated that ewes have the capacity to sustain growth and nutrition of multiple foetuses during severe energy restriction in late pregnancy, but apparently the capacity to produce milk for the lambs after birth may be compromised.

\title{
BERBERIS VULGARIS AS FEED ADDITIVE IN POULTRY PRODUCTION
}

\author{
Rajaian, H., Jalaee, J. and Aghajani, M. \\ School of Veterinary Medicine, Shiraz University, Shiraz, Iran
}

Berberis vulgaris (Zereshk in Persian) is a member of therapeutic plants in herbal medicine. There is evidence that its root contains components, such as berberine, berbamine, culumbamine and berberubine, with a relatively wide spectrum of antimicrobial activity. Antibiotics, mainly those that are not used for disease control in animals and/or humans, are added to animal feed to promote their growth. The aim of the present study was to examine if the plant root has any effect on the growth of broiler chickens. The plant was collected from Shiraz area in sufficient quantity and the roots were dried at room temperature and then ground into a powder. The root powder was added to the proper chicken ration, depending on the age of birds, in various concentrations (one and two percents). Oneday-old broiler chickens were randomly divided into seven groups (twenty chickens each) and were reared under similar conditions. The chickens in the first group received normal ration not containing the root powder. Second, third and fourth groups were fed a ration containing $1 \%$ root powder starting from first day, 18th day and 36th day, respectively. The other three groups were treated similarly but with the ration containing $2 \%$ root powder. Chickens were weighed every five days until the age of 50. Statistical comparison of average body weights in each group showed that chickens in group two (fed the ration containing $1 \%$ root powder from day one) were significantly $(\mathrm{P}<0.05)$ heavier than the birds in other groups. There may be at least two reasons why the rations containing $2 \%$ root powder were not as effective as those containing $1 \%$. First, the higher concentration of powder possibly decreases the palatability of the feed; and second, a higher percent of the ration is composed of less nutritive value. Although economical, but it may not be practical to recommend the usage of the plant root as a source of feed additive. Therefore, it is suggested to examine the effect of active ingredients of the plant in this respect. In addition, individual follow-up of weight gain, determination of feed conversion factor, and sex of the birds should be considered in the future work. 